\title{
Resveratrol as a potential broad-spectrum compound for cancer treatment
}

\author{
Li Kar Stella Tan ${ }^{1}$, Chee Wun How ${ }^{2}$, Jhi Biau Foo ${ }^{1}$, Kooi Yeong Khaw ${ }^{3,6}$, Bey-Hing Goh ${ }^{4,5,6}$ and Yong \\ Sze Ong ${ }^{4,6 *}$ \\ ${ }^{1}$ School of Pharmacy, Faculty of Health \& Medical Sciences, Taylor's University, 47500 Subang Jaya, Selangor, Malaysia \\ ${ }^{2}$ School of Pharmacy, Monash University Malaysia, 47500 Bandar Sunway, Selangor, Malaysia \\ ${ }^{3}$ Tropical Medicine \& Biology Platform, Monash University Malaysia, 47500 Bandar Sunway, Malaysia \\ ${ }^{4}$ Health and Well-Being Cluster, Global Asia in the 21st Century (GA21) Platform, Monash University Malaysia, 47500 \\ Bandar Sunway, Malaysia \\ ${ }^{5}$ College of Pharmaceutical Sciences, Zhejiang University, 866 Yuhangtang Road, Hangzhou 310058, China \\ ${ }^{6}$ Biofunctional Molecule Exploratory (BMEX) Research Group, School of Pharmacy, Monash University Malaysia, Bandar \\ Sunway, Selangor, Malaysia
}

\begin{abstract}
There is a need to shift the paradigm of cancer therapeutic approach. The severe adverse side effects, drug resistance and unaffordable price plagued with chemotherapeutic drugs has spurred the development of "dirty drug". Natural products, specifically phytochemicals, have gained much attention due to their ability to target multiple interconnected pathways. Resveratrol (RSV), the stilbenes found in red wine, is one of the phytochemicals that exhibits various pharmacological therapeutic effects including cancer. In this review, we highlighted RSV as a potential "broad-spectrum" anticancer compound, by summarising its targeting mechanisms in the pathways relevant to the cancer hallmarks.
\end{abstract}

Keywords: stilbene; hallmarks; dirty drug; natural product; metabolites

Received: $8^{\text {th }}$ June 2020

Accepted: $8^{\text {th }}$ July 2020

Published Online: $18^{\text {th }}$ July 2020
*Correspondence: Yong Sze Ong, School of Pharmacy, Monash University Malaysia, 47500, Bandar Sunway, Selangor Darul Ehsan, Malaysia; ong.yong.sze@monash.edu.

Citation: Tan LKS, How CW, Foo JB, et al. Resveratrol as a potential broad-spectrum compound for Cancer treatment. Prog Microbes Mol Biol 2020; 3(1): a0000098. https://doi.org/10.3687/pmmb.a0000098.

\section{INTRODUCTION}

Cancer, the most commonly diagnosed non-communicable disease, has imparted significant mortality and morbidity worldwide ${ }^{[1]}$. In 2018, the World Health Organisation ranked cancers as the leading cause of premature death with 9.6 million cases reported worldwide ${ }^{[2]}$. Despite the advancement in cancer therapy, the overall survival rate and quality of life of cancer patients have not been improved. The development of personalised drug on the other hand, is slow, costly and may not guarantee good clinical outcomes. Particular attention has been devoted to explore the potential of pleiotropic, "broadspectrum" compounds or "dirty drugs" which could simultaneously target multiple mechanisms to overcome the aforementioned issues in achieving effective cancer treatment ${ }^{[3]}$.

The ten cancer hallmarks proposed by Hanahan and Weinberg in 2011, has become a general a guide to evaluate the potential of specific compound as a promising "dirty drug"[4]. This means compounds that could disrupt any of the processes responsible for the cancer hallmarks would almost certainly hinder cancer progression. In an ideal circumstance, a compound that could disrupt multiple pathways not only would produce superior effect, it would also minimise the risk of side effects that is otherwise introduced by multiple drug administration. Natural products have been a rich and excellent source to search for multi-target bioactive compounds with improved therapeutic efficacy and safety ${ }^{[5,6]}$. These multi-target bioactive compounds are derived from natural sources such as plants ${ }^{[7,8]}$, microorganisms ${ }^{[9-16]}$ and animals ${ }^{[17]}$. In a work published by Block et al. $(2015)^{[3]}$, they found that most of the compounds that targets all cancer hallmarks were the phytochemicals. Phytochemicals are naturally produced as a result of evolution against pathogens with evident role playing in human health. These natural compounds have attracted much attention from community for their promising effects in treating diseases ${ }^{[18-22]}$. Stilbenes are one of the examples of secondary metabolites that was produced in stressful condition to fight against fungal infection and UV radiation ${ }^{[23]}$. It is one of the nonflavonoids which consists of two aromatic rings linked by an ethylene 
or ethane bridge (C6-C2-C6 carbon skeleton) and usually found in plants. Among the 400 natural stilbenes discovered, RSV is the most widely investigated compound due to its vast pharmacological activities ${ }^{[24]}$.

\section{RESVERATROL}

Resveratrol (3,4',5-trihydroxy-trans-stillbene) (RSV) (Figure 1) can be found in the skin of grapes, red wines, peanuts, pineapple and mulberries. This compound could be synthesised from phenylalanine pathway through several enzyme reactions into para-coumaroyl-CoA, which is condensed with malonyl CoA to form RSV ${ }^{[25]}$. Since the discovery of RSV by Siemann and Creasy in red wine in $1992^{[26]}$, extensive studies have proven that RSV exhibits its biological functions such as antimicrobial, cardiovascular disease, anticancer, anti-inflammatory, antidiabetic and neurodegenerative diseases ${ }^{[27,28]}$. It is believed that most of the pharmacological activities are attributed to its anti-oxidant mechanisms involving the competition with coenzyme $\mathrm{Q}$, free radical scavenging and inhibition of lipid peroxidase in the mitochondria ${ }^{[29]}$. in vitro and in vivo settings. The type of cancers tested are ovarian ${ }^{[30]}$, lung ${ }^{[31]}$, colon ${ }^{[32]}$, prostate $^{[33]}$, breast ${ }^{[34]}$ and cervical cancers ${ }^{[35]}$. As a pleiotropic compound which acts on different mechanisms, it also showed to play a possible role to counteract multidrug resistance ${ }^{[36]}$. As of June 2020, the keywords of "resveratrol and cancer" brings up 3660 results in PubMed database. Correspondingly, RSV possesses great commercial value as evidence by a surge in patent filed in The Lens patent database (http://lens. org) related to the application of RSV in cancer therapy in recent decades (Figure 2).

\section{MODULATION OF CANCER HALLMARKS}

The surge of publications and patents undeniable reflect the increased interest of the scientific community toward the therapeutic effect of RSV. In an attempt to investigate the potential of RSV as a "broad spectrum" chemotherapeutic agent, this review summarised the cancer hallmarks and the target molecules that have been claimed to be modulated by RSV in various cancer cell lines and animal models (Figure 3).

RSV has demonstrated anti-cancer properties in both

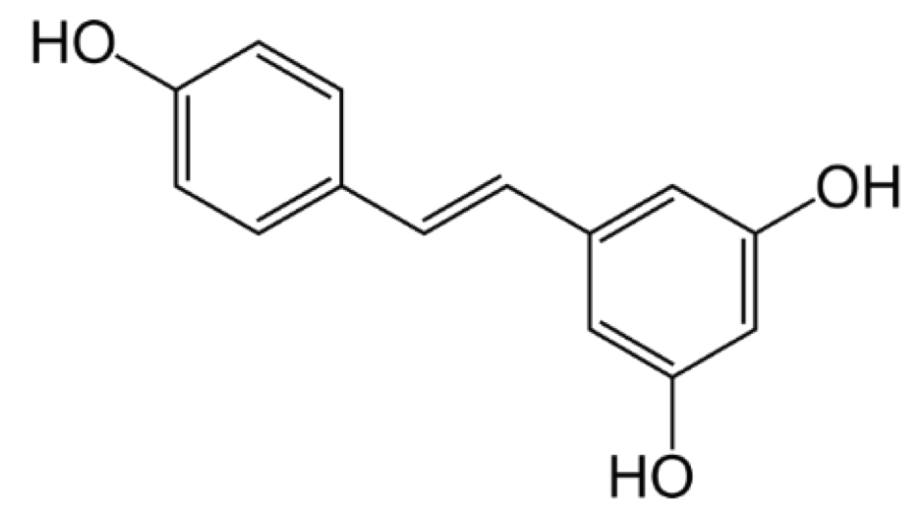

Figure 1. Chemical structure of resveratrol.

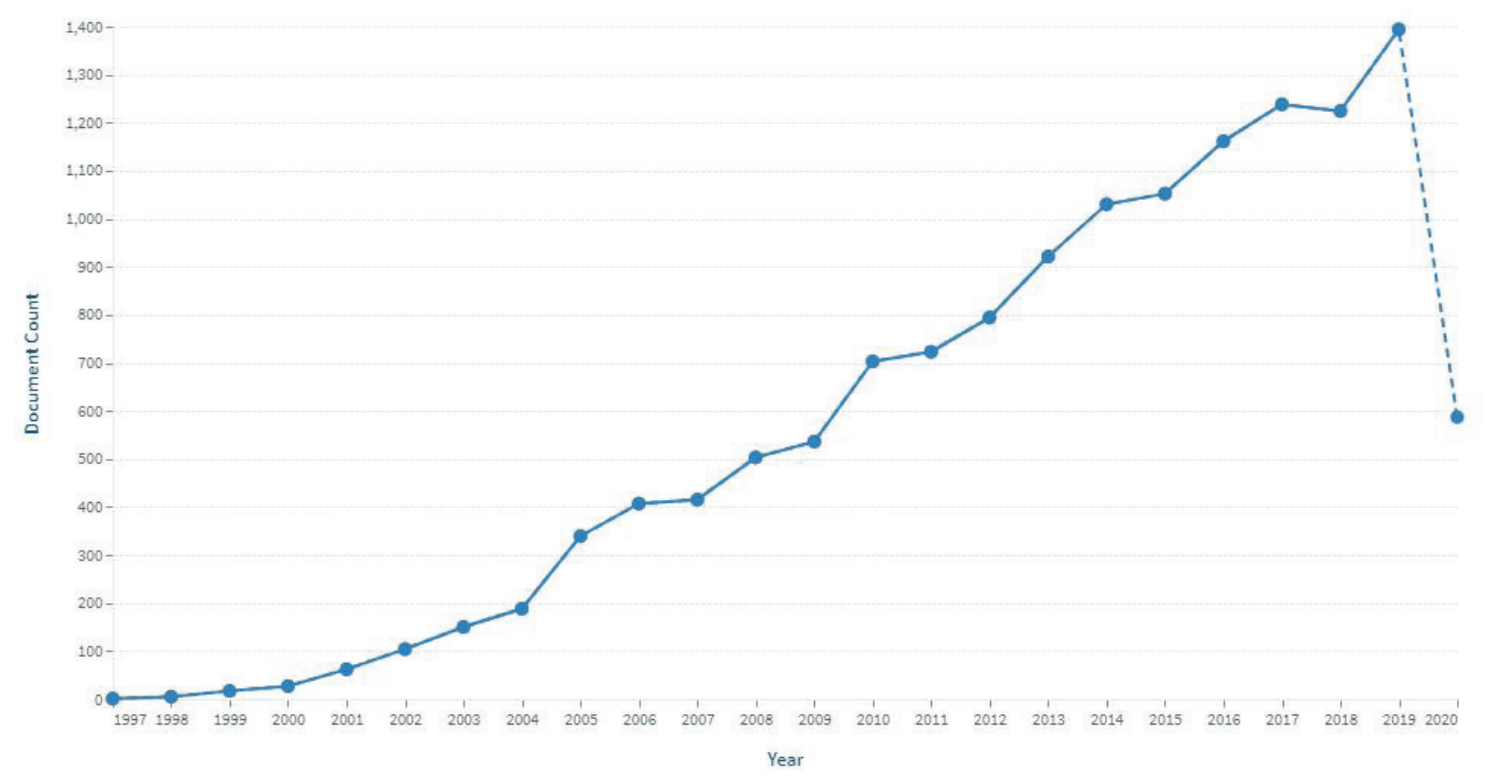

Figure 2. Number of patents filed with keywords "resveratrol" and "cancer" from 1997 to 2020. Data was obtained from The Lens patent search engine. 


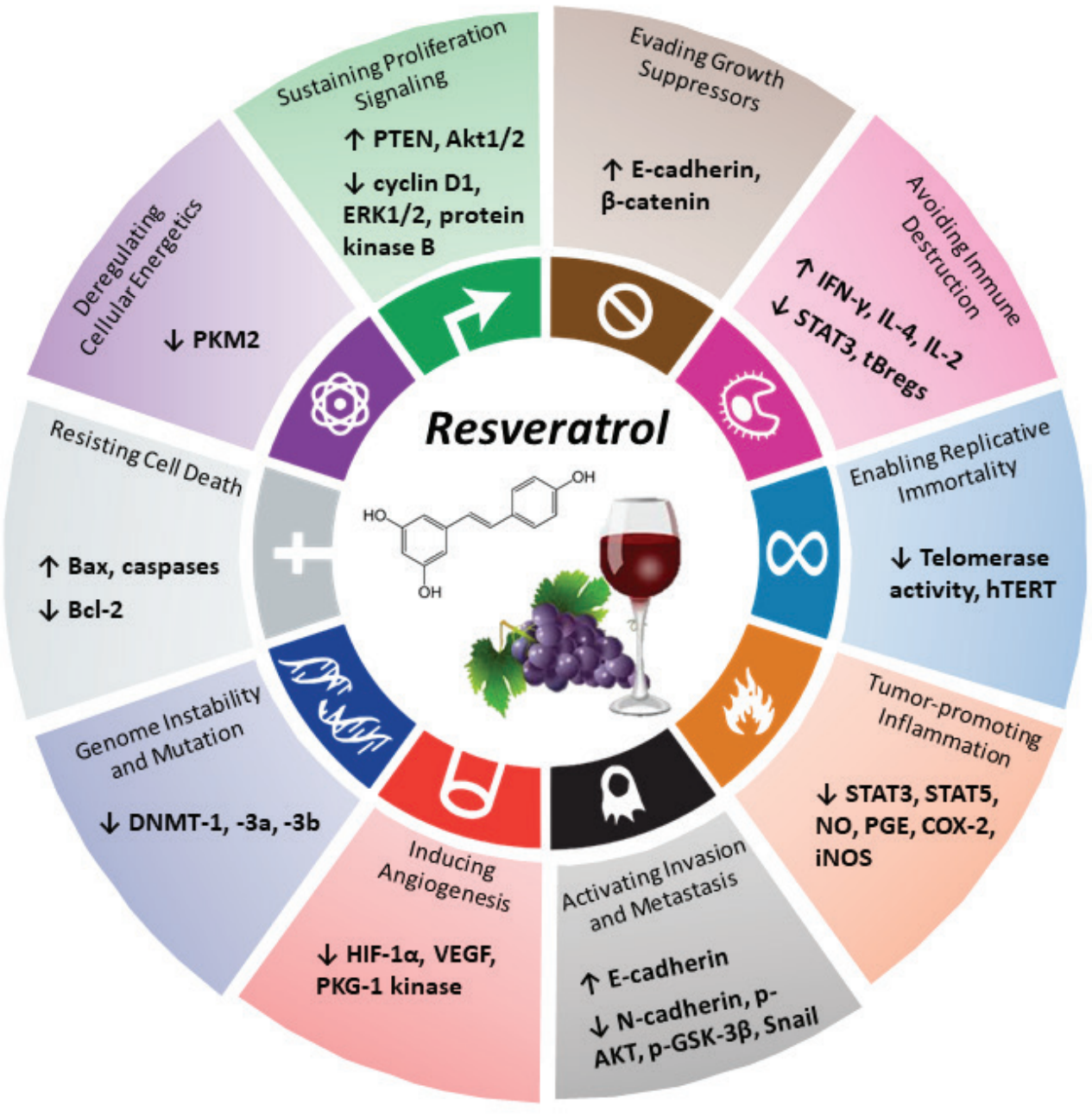

Figure 3. Cancer hallmarks and molecular targets modulated by resveratrol.

\section{Prevention of Proliferative Signalling}

Most cancer cells have upregulated proliferative signalling pathways in order to maintain their survival. The signalling pathways are often associated to the alteration in the expression of proteins related to cell cycle, metabolism and cell proliferation ${ }^{[37-39]}$. RSV promoted the growth of ovarian cancer cell (OVCAR-3) by blocking $\mathrm{PI} 3 \mathrm{~K}$ and Akt signalling pathways, through reduction of phosphorylated extracellular signal-regulated kinase (ERK)1/2, downregulation of cyclin D1 and protein kinase $\mathrm{B}^{[40]}$. Cancer cells have prevented the proliferation via activation of autophagy-suppressing pathway such as phosphatidylinositol 3-kinase (PI3K)/Mammalian Target of Rapamycin (mTOR $)^{[30]}$. Autophagy has become a target that may play an important role in cancer treatment. Studies have shown that RSV could induce autophagy cell death. Zhang and the research team proved that the treatment with RSV caused accumulation of calcium ions which then led to the activation of phosphorylated AMPK and phosphorylated Raptor via $\mathrm{Ca}^{2+} / \mathrm{AMPK}$-mTOR signalling pathway in the A549 human lung adenocarcinoma cells ${ }^{[31]}$. The anti-proliferative effect of RSV has been determined in xenograft animal model (HCT116 colon cancer cells in athymic nude mice). The RSV induced the gene expression of PTEN, the tumour suppressor gene, which then led to the downregulation PI3K/Akt signalling evidenced by the phosphorylation of $\mathrm{Akt1} / 2^{[32]}$.

\section{Activation of Growth Suppressors}

On top of sustaining the proliferation, the cancerous cells are also overpowered the growth suppression pathway. There are two commonly known mechanisms of tumour suppressors, the retinoblastoma-associated (RB) and TP53 proteins. These proteins prevent the progression of cancerous cells growth through cell cycle arrest and cell death via induction of apoptosis. Evidence suggests that RSV induces cell death through the activation of p53 pathway, which further triggered apoptosis via mitogen-activated protein (MAP) kinases in T98G glioblastoma cells ${ }^{[41]}$. The results were in congruent to with another study in which the p53-dependent apoptosis was activated due to the binding of RSV to integrin $\alpha \mathrm{V} \beta 3$, more specifically the $\beta 3$ monomer ${ }^{[42]}$.

Research found that the abruption and suppression in the transforming growth factor $\beta$ (TGF- $\beta$ ) and "contact inhibition" pathway which involve E-cadherin and epidermal growth factor (EGF) receptors has led to the proliferation of cancerous cells ${ }^{[36]}$. Zhong et al. $(2015)^{[43]}$ postulated that RSV suppressed the proliferation of OVAR3 ovarian cancer 
cells by upregulated the protein expression of E-cadherin which subsequently increased the $\beta$-catenin on the cell membrane, leading to the inhibition of proliferation.

\section{Promotion of Cancerous Cell Death}

Normal cells maintain the homeostasis by programmed cell death through apoptosis. However, this normal cellular homeostasis is abrogated during tumorigenesis. Cancerous cells modulate the regulatory and effector components in the cell via increase the anti-apoptotic proteins such as $\mathrm{Bcl}-2$ and downregulate the proapoptotic proteins such as Bax, Puma, Bim and caspases. Induction of apoptosis is considered as one of the strategies in cancer treatment due to the minimal inflammatory response ${ }^{[18]}$. Convincing evidences showed that RSV induced apoptosis in various cancer cells such as $\mathrm{T}$ acute lymphoblastic leukaemia cell line $\mathrm{e}^{[44]}$, HCT116 colorectal carcinoma cell[ ${ }^{[5]}$, Caco-2 colorectal cancer cells ${ }^{[46]}$, TRAMP murine prostate cancer cells ${ }^{[33]}$ and MCF-7 breast cancer cell ${ }^{[34]}$ through upregulation of Bax and downregulation of Bcl-2 expression. Some studies have suggested that the changes in the expression on both Bax and Bcl-2 were due to the disruption in the mitochondria membrane potential $(\Delta \psi \mathrm{m})$ after treatment with $\operatorname{RSV}^{[33]}$

Apart from apoptosis, autophagy plays an important role in maintaining the cellular homeostasis by clearing up the aggregated proteins, damaged organelles or exogenous components via a lysosomal degradation process $^{[30]}$. Studies suggested that RSV could be a natural autophagy agent. Luyten and the research team found out that RSV induced autophagy via mTOR-dependent pathway with the presence of $\mathrm{IP}_{3} \mathrm{Rs}$ and extracellular $\mathrm{Ca}^{2+}$ in HeLa human cervix carcinoma cells ${ }^{[35]}$. The results is in compliance with Park et al. (2016) $)^{[47]}$ in which they suggested that RSV inhibited mTOR by directly docking onto the ATP-biding site of $\mathrm{mTOR}^{[47]}$

\section{Disabling Replicative Immortality}

Telomeres have long been regarded as the guardian of genome stability. The telomere theory of aging and longevity of cells is well-recognised through its ability to elongate the $\mathrm{DNA}^{[48]}$. Notwithstanding, the association of telomeres with cancer has been suggested in several studies that consistently demonstrated that the tumour cells contains higher percentage of telomerase activity as compared to normal cells. These observations strengthened the coherency that explains the immortality of cancerous cells. The understanding of the mechanisms underlying telomerase activity and telomere structures have offered another option for cancer therapy ${ }^{[49]}$. Wang et al. (2011) ${ }^{[50]}$ reported that RSV delayed the senescence of endothelial progenitor cells isolated from human peripheral blood via the downregulation of telomerase activity. The study also suggested that the compound has regulated the expression of human telomerase reverse transcriptase (hTERT), the rate limiting component of telomerase activity, via the PI3K/Akt pathway ${ }^{[50]}$. The results were in accordance to Mirzazadeh et al. (2017) ${ }^{[49]}$ in which they pointed out the role of RSV in regulating the replication immortality by inhibition of the hTERT gene expression in a dose-dependent manner in human glioblastoma cell line U-87MG ${ }^{[49]}$.

\section{Inhibition of Angiogenesis}

One of the vital components for cancer development and progression is the formation of blood vessels (angiogenesis) in the tumour area. Cancerous cells regulate the pro-angiogenic factors such as vascular endothelial growth factor (VEGF) to stimulate vascular endothelial cells to enter the tumour hypoxic areas and anti-angiogenic factors such as thrombospondin-1 (TSP1) to inhibit the effect of VEGF ${ }^{[51]}$. Studies showed that treatment with RSV has decreased the stabilisation of hypoxia-inducible factor- 1 (HIF-1 $\alpha$ ) which in turn downregulated the VEGF protein expression and upregulated the TSP1 protein expression in spheroid A375 melanoma cells ${ }^{[52]}$. Another study by Mikuła-Pietrasik et al. $(2012)^{[53]}$ suggested that RSV suppressed the angiogenesis by downregulating IL-8/ CXCL-8, the proangiogenic chemokine which regulated the expression of VEGF, in human peritoneal mesothelial cells (HUVEC, HMVEC and HMEC-1) ${ }^{[53]}$. A combination of RSV with 5-fluorouracil (5FU) has enhanced the in vitro anti-angiogenic effect in B16 melanoma cells, as compared to treatment with either drug alone. The results demonstrated that the combined treatment has synergistically decreased the VEGF protein expression. As a proof of concept, further study was performed with B16 tumour-bearing BALB/c nude mice in the effort to assess the in vivo anti-angiogenic effect. After subcutaneous injection for 10 days, the combined treatment of RSV and 5FU has significantly decreased the VEGF protein expression with reduced microvessel density as compared to the negative control group ${ }^{[54]}$. RSV has shown its antiangiogenic effect by inhibiting the tube formation and cell migration in primary human vascular endothelial cells (HUVECs). The authors reported that the process was achieved by the suppression of PKG-1 kinase and four inhibitors of apoptosis proteins (c-IAP1, c-IAP2, livin and XIAP) $)^{[5]}$

\section{Deactivation of Invasion and Metastasis}

Epithelial-mesenchymal transition (EMT) is a process where the epithelial cells lose the cell-cell contact by exhibiting mesenchymal phenotype. This process potentially worsen the prognosis in cancer patients by enhancing the invasiveness and migration of cancerous cells $^{[56]}$. Several studies have confirmed that RSV inhibited metastasis and invasion in various cancer cells through EMT signalling pathway ${ }^{[57-59]}$. Yuan and team proved that RSV reversed EMT via regulation of AKT/GSK$3 \beta /$ Snail signalling pathway both in vitro colon cancer cells (SW480 and SW620) and in vivo lung metastasis animal model (SW480 tumor bearing nude mice) ${ }^{[58]}$. The effect was verified using proteomic experiments, indicating that the treatment with RSV has upregulated the expression of E-Cadherin and downregulated the expression of N-cadherin, p-AKT, p-GSK-3 $\beta$ and Snail in both models ${ }^{[58]}$. Another key regulator, the metastasisassociated protein 1 (MTA1), is also known to correlate with the aggressiveness of the tumour metastasis. Li et al. $(2013)^{[60]}$ has first demonstrated that RSV modulated the expression of MTA1-mediated proteins such as Ac-p53 in 
prostate cancer xenografts animal model, consolidating the ability of RSV in deactivation of metastasis.

\section{Epigenetic Modification}

Epigenetic modification such as DNA methylation and histone modification are the important key regulators in affecting tumorigenesis ${ }^{[61]}$. A number of research has been done to investigate the interaction of RSV with epigenetic targets such as DNA methyltransferase (DNMT), histone deacetylase (HDAC) and lysine-specific demethylase-1 (LSD-1) in regulating the histone proteins and DNA molecules ${ }^{[62]}$. RSV showed its ability to reverse carcinogenesis by significantly reducing the DNMT mRNA expression (DNMT1, DNMT3a and DNMT3b) in human breast cancer cell lines (MCF-7 and MDAMB-231), evidenced by Mirza et al. (2013) ${ }^{[63]}$. Similarly, in combination of another plant-based pterostilbene, RSV has significantly decreased the activation of DNMT enzyme via restoration of oestrogen receptor- $\alpha(E R \alpha)$ expression in ER $\alpha$-negative breast cancer MDA-MB-157 cell line ${ }^{[64]}$.

\section{Ameliorating the Tumour-Promoting Inflamma- tion}

Studies showed that $25 \%$ of the cancer occurred due to the chronic inflammation as a result of simultaneous destruction and healing of body tissues. Tumour-associated inflammation is always linked with poor prognosis ${ }^{[65-67]}$. Signal transducer and activators of transcription (STAT) and NF- $\mathrm{KB}$ signalling pathways are the two promising targets for cancer therapy as both collaboratively play role in inflammatory response via inducing the expression of pro-tumorigenenic genes such as $I L-1 \beta, C O X-2$ and cyclin D1. Many studies have been focusing on the effect of polyphenols including RSV in tumour-associated inflammation. RSV has shown its efficacy by suppressing both STAT3 and STAT5 phosphorylation in 786-O renal cell carcinoma cells as evidenced by Kim et al. (2016) ${ }^{[68]}$. It also co-regulated both STAT3 and NF- $\kappa$ B pathways in medulloblastoma UW228-2 and UW228-3 cell lines, which subsequently lead to the up-regulation of Bcl-2 protein expression ${ }^{[69]}$. Interestingly, RSV also regulated JAK-STAT pathway in colon cancer HT-29 cell line with significantly reduced expression level of nitric oxide, prostaglandin $\mathrm{E}_{2}$, inducible nitric oxide synthase (iNOS) and cyclooxygenase-2 (COX-2), consolidating the effect of RSV in inflammatory process in various cancers.

\section{Programming Energy Metabolism}

Warburg effect was observed in cancer where the cells altered energy metabolisms, including increased glycolysis and lactate production, to cope with their growth requirements. Therefore, the proteins that are involved in the metabolism become the key elements in tumour progression and therapeutic targets for cancer treatment ${ }^{[70-72]}$. Saunier et al. (2017) ${ }^{[70]}$ proved that RSV managed to reverse Warburg effect via activation of pyruvate dehydrogenase in colon cancer Caco 2 cells. Interestingly, the reversal effect could be observed even with low doses of RSV that mimicked the drug concentration in human patients ${ }^{[70]}$. Another study proposed that RSV modulated the Warburg effect via mTOR signalling pathway by down-regulation of pyruvate kinase M2 (PKM2), a catalyst in converting the phosphoenol-pyruvate to pyruvate ${ }^{[73]}$, in cervical cancer HeLa, liver carcinoma HepG2 and breast cancer MCF-7 cell lines ${ }^{[74]}$.

\section{Promotion of Immune Destruction}

In normal cells, immune system acts as a surveillance to protect our body from against foreign microorganisms. In events where infection occurs, the immune system will initiate a series of mechanism to eliminate the source of infection. Principally, the immune cells could mount a response in eliminating the cancer cells which are recognised as "non-self" [75]. However, the cancerous cells gain ability to alter the immune system through several mechanisms such as modulating the expression of major histocompatibility class (MHC1) or immunosuppressive products ${ }^{[76]}$ (Print. Studies have suggested that RSV could modulate the molecular modulators of the inflammatory response in vitro and in vivo, via the activation of macrophage, $\mathrm{T}$ cells and natural killer ${ }^{[77]}$. RSV suppressed the proliferation of cancerous cells via the secretion of IFN- $\gamma$, IL-4, IL$2, \mathrm{CD} 4+$ in lymphocytes and elevated the secretion IL10 via downregulation of the CD80 on macrophages ${ }^{[78]}$. The compound was proven to enhance the expression of Fc $\gamma$ RIIB, a receptor for IgG that blocks the activation of $\mathrm{B}$ cells in mice ${ }^{[79]}$. As a result of the regulation of immune system, Lee-Chang et al. (2013 ${ }^{[80]}$ showed that RSV could inhibit the lung metastasis in 4T1-tumor bearing BALB/c mice via inhibition of phosphorylation of STAT3 and hence inactivation of $\mathrm{tBregs}^{[80]}$.

\section{MOVING TOWARDS CLINICAL TRIALS}

In order to realise the clinical translation for cancer therapy, the toxicity of RSV have been investigated to gauge its safety and effectiveness in both the animals and human. A commercialised RSV (ResVida) was found to have noobserved-adverse effect levels (NOAELs) of $750 \mathrm{mg} / \mathrm{kg}$ / bw in rats via oral administration, which then converted to human equivalent dose of $450 \mathrm{mg} / \mathrm{kg}^{[81]}$. At higher dose of $3,000 \mathrm{mg} / \mathrm{kg}$, oral administration of RSV does seem to caused renal and bladder toxicity after a daily administration for one month in rats ${ }^{[82]}$. In human, the oral consumption of 5 $\mathrm{g}$ of SRT501, a proprietary micronised formulation of RSV by GlaxoSmithKline (GSK) for 14 days are well-tolerated in colorectal cancer patients ${ }^{[83]}$. However, the toxicity seems to be largely affected by the pre-existing conditions of patients. For instance, one clinical trial that recruited subjects with multiple myeloma was prematurely terminated due to high incidence of renal toxicity after given a dose of RSV similar to SRT501. The patients had experienced an elevated serum creatinine level with more than $500 \mu \mathrm{mol} / \mathrm{L}$ with minority developed crystal nephropathy and acute tubular damage ${ }^{[84]}$. The toxic effect is believed to happen specifically to multiple myeloma patients which had developed pre-existing renal damage prior to the treatment.

A number of clinical trials have been conducted in recent decades to investigate the anti-cancer effect of RSV. Table 1 summarizes the clinical trials involved the use of resveratrol as a single therapeutic agent or combination therapy in cancer treatment: 
Table 1. Clinical trials of resveratrol in cancer treatment, data retrieved from https://clinicaltrials.gov/.

\begin{tabular}{|c|c|c|c|c|}
\hline Type of cancer & Phase and status & Treatment & Outcome & Ref. \\
\hline Colon & Phase I (Completed) & $\begin{array}{l}\text { - Oral administration of } 20,80,160 \mathrm{mg} / \text { day } \\
\text { of RSV } \\
\text { - Two weeks treatment }\end{array}$ & $\begin{array}{l}\text { Significant inhibition of the gene expres- } \\
\text { sion of Wnt target in colonic mucosa }\end{array}$ & {$[85]$} \\
\hline Colon and Rectal & Phase I (Completed) & $\begin{array}{l}\text { - Treatment is given after surgical resection } \\
\text { - Oral administration of RSV for } 9 \text { days } \\
\text { continuously (dose is not mentioned) }\end{array}$ & Outcome is not provided & - \\
\hline Multiple Myeloma & Phase II (Terminated) & $\begin{array}{l}\text { Oral administration of } 5.0 \mathrm{~g} \text { SRT501 } \\
\text { (RSV) for } 20 \text { days }\end{array}$ & $\begin{array}{l}\text { The trial was terminated due to reported } \\
\text { renal toxicity }\end{array}$ & [84] \\
\hline $\begin{array}{l}\text { Lymphangioleiomyo- } \\
\text { matosis }\end{array}$ & Phase II (Recruiting) & $\begin{array}{l}\text { - Escalating doses of RSV from } 250 \mathrm{mg} \\
\text { daily (for } 8 \text { weeks, } 500 \mathrm{mg} \text { daily ( } 8 \text { weeks) } \\
\text { and } 500 \mathrm{mg} \text { twice a day (for } 8 \text { weeks) } \\
\text { - (Route of administration is not reported) }\end{array}$ & Outcome is not yet reported & - \\
\hline $\begin{array}{l}\text { Polycystic ovary } \\
\text { syndrome }\end{array}$ & Phase 4 (Recruiting) & $\begin{array}{l}\text { - A combination treatment of } 500 \mathrm{mg} \text { of } \\
\text { RSV and } 20 \mathrm{mg} \text { simvastatin daily } \\
\text { - (Route of administration is not reported) }\end{array}$ & Outcome is not yet reported & - \\
\hline
\end{tabular}

\section{CONCLUSION}

Currently, the search and development of a more effective cancer therapeutic regimen with low toxicity and "broad spectrum" that could simultaneously target several mechanisms has been encouraged in response to the intolerable conventional chemotherapy. The cancer hallmarks have been adopted to provide a clear insight in understanding the potential of specific compounds as "dirty drugs" on the molecular basis. As can be seen, RSV was found to be interfering with all the cancer hallmarks and modulating the key signalling pathways in tumour development, hence suggesting that the compound hold a great promise for future anticancer drug development. On top of that, several studies have found that RSV exhibit synergistic anticancer effect when combined with other therapeutic agents. Even though the preclinical studies showed promising results, the compound has been disappointing with its toxicity and poor pharmacokinetics in human. We believe that RSV should be considered favourably as a broad-spectrum chemotherapeutic agent that might overcome the limitations of conventional treatment. The drug design and delivery formulation of this compound should be further improved for clinical translation.

\section{Acknowledgements}

The authors would like to acknowledge Monash Tropical Medicine \& Biology (TMB) Multidisciplinary Platform and Monash Global Asia in the 21st Century (GA21) research grant (GA-HW-19-L-01 and GA-HW-19-S02) for this study.

\section{Conflict of interest}

The authors declare that there is no conflict of interest.

\section{References}

1. World Health Organisation. Global status report on noncommunicable diseases 2014. 2014 06/07/2020]; Available from: https://www.who. int/nmh/publications/ncd-status-report-2014/en/.

2. Bray F, Ferlay J, Soerjomataram I, et al. Global cancer statistics 2018: GLOBOCAN estimates of incidence and mortality worldwide for 36 cancers in 185 countries. Ca-Cancer J Clin 2018; 68(6): 394-424.

3. Block KI, Gyllenhaal C, Lowe L, et al. Designing a broad-spectrum integrative approach for cancer prevention and treatment. Semin Cancer Biol 2015; 35 Suppl(Suppl): S276-S304.

4. Hanahan D and Weinberg Robert A. Hallmarks of Cancer: The Next Generation. Cell 2011; 144(5): 646-674.

5. Goh JXH, Tan LT-H, Goh JK, et al. Nobiletin and derivatives: Functional compounds from citrus fruit peel for colon cancer chemoprevention. Cancers (Basel) 2019; 11(6): 867

6. Chan W-K, Tan LT-H, Chan K-G, et al. Nerolidol: A sesquiterpene alcohol with multi-faceted pharmacological and biological activities. Molecules 2016; 21(5): 529.

7. Mahendra CK, Tan LTH, Lee WL, et al. Angelicin-A Furocoumarin compound with vast biological potential. Front Pharmacol 2020; 11.

8. Tay K-C, Tan LT-H, Chan CK, et al. Formononetin: A review of its anticancer potentials and mechanisms. Front Pharmacol 2019; 10.

9. Law JW-F, Letchumanan V, Tan LT-H, et al. The rising of "modern actinobacteria" era. Prog Microbes Mol Biol 2020; 3(1).

10. Tan LT-H, Lee L-H and Goh B-H. Critical review of fermentation and extraction of anti-Vibrio compounds from Streptomyces. Prog Microbes Mol Biol 2020; 3(1).

11. Kemung HM, Tan LT-H, Chan K-G, et al. Investigating the antioxidant potential of Streptomyces sp. MUSC 11 from mangrove soil in Malaysia. Prog Drug Discov Biomed Sci 2019; 2(1).

12. Tan LT-H, Lee L-H and Goh B-H. The bioprospecting of anti-Vibrio Streptomyces species: Prevalence and applications. Prog Microbes Mol Biol 2019; 2(1).

13. Tan LTH, Mahendra CK, Yow YY, et al. Streptomyces sp. MUM273b: A mangrove $\square$ derived potential source for antioxidant and UVB radiation protectants. MicrobiologyOpen 2019; 8(10): e859.

14. Tan LT-H, Chan C-K, Chan K-G, et al. Streptomyces sp. MUM256: A source for apoptosis inducing and cell cycle-arresting bioactive compounds against colon cancer cells. Cancers (Basel) 2019; 11(11): 1742 .

15. Ong K-S, Letchumanan V, Law JW-F, et al. Microbes from Peat Swamp Forest-The Hidden Reservoir for Secondary Metabolites? Prog Microbes Mol Biol 2020; 3(1).

16. Tan LT-H, Chan K-G, Pusparajah P, et al. Mangrove derived Streptomyces sp. MUM265 as a potential source of antioxidant and anticolon-cancer agents. BMC Microbiol 2019; 19(1): 38 .

17. Chee PY, Mang M, Teng Hern TL, et al. Epinecidin-1, An antimicrobial peptide derived from grouper (Epinephelus coioides): Pharmacological activities and applications. Front Microbiol 2019; 10: 2631.

18. Ong YS, Yazan LS, Ng WK, et al. Thymoquinone loaded in nanostructured lipid carrier showed enhanced anticancer activity in 4T1 tumor-bearing mice. Nanomed2018; 13(13): 1567-1582.

19. Khaw KY, Ong YS and Goh B-H. A rapid method for the retrieval of bioactive Xanthone from Garcinia Mangostana: A case study of $\alpha$-Mangostin. Prog Drug Discov Biomed Sci 2020; 3(1).

20. Tan LT-H, Khaw KY, Ong YS, et al. An Overview of Clinacanthus nutans (Burm. f.) Lindau as a Medicinal Plant with Diverse Pharmacological Values, in Plant-derived Bioactives. 2020, Springer. 
p. $461-491$

21. Mahendra CK, Tan LT-H, Yap WH, et al. Model of experimentation for photoprotective properties of natural products against Ultraviolet C (UVC) Damage: A case study on Rosmarinic Acid. Prog Drug Discov Biomed Sci 2019; 2(1).

22. Tan LTH, Low LE, Tang SY, et al. A reliable and affordable 3D tumor spheroid model for natural product drug discovery: A case study of curcumin. Prog Drug Discov Biomed Sci 2019; 2(1).

23. Hosseini A and Ghorbani A. Cancer therapy with phytochemicals: Evidence from clinical studies. Avicenna J Phytomed 2015; 5(2): 84-97.

24. Morabito G, Miglio C, Peluso I, et al. Chapter 85 - Fruit Polyphenols and Postprandial Inflammatory Stress, in Polyphenols in Human Health and Disease, R.R. Watson, V.R. Preedy, and S. Zibadi, Editors. 2014, Academic Press: San Diego. p. 1107-1126.

25. Jeandet P, Delaunois B, Aziz A, et al. Metabolic engineering of yeast and plants for the production of the biologically active Hydroxystilbene, Resveratrol. J Biomed Biotechnol 2012; 2012: 579089.

26. Gehm BD, McAndrews JM, Chien P-Y, et al. Resveratrol, A polyphenolic compound found in grapes and wine, is an agonis for the estrogen receptor. Proc Natl Acad Sci 1997; 94(25): 14138-14143.

27. Xia N, Daiber A, Förstermann U, et al. Antioxidant effects of resveratrol in the cardiovascular system. Br J Pharmacol 2017, 174(12): 1633-1646.

28. Ma DS, Tan LT-H, Chan K-G, et al. Resveratrol-Potential antibacterial agent against foodborne pathogens. Front Pharmacol 2018; 9: 102.

29. De la Lastra CA and Villegas I. Resveratrol as an antioxidant and pro-oxidant agent: Mechanisms and clinical implications. Biochem Soc Trans 2007; 35(5): 1156-1160.

30. Levine B and Kroemer G. Autophagy in the pathogenesis of disease. Cell 2008; 132(1): 27-42.

31. Zhang J, Chiu J, Zhang $\mathrm{H}$, et al. Autophagic cell death induced by resveratrol depends on the $\mathrm{Ca}(2+) / \mathrm{AMPK} / \mathrm{mTOR}$ pathway in A549 cells. Biochem Pharmacol 2013; 86(2): 317-328.

32. Liu YZ, Wu K, Huang J, et al. The PTEN/PI3K/Akt and Wnt/ $\beta$ catenin signaling pathways are involved in the inhibitory effect of resveratrol on human colon cancer cell proliferation. Int J Oncol 2014; 45(1): 104-112.

33. Kumar S, Eroglu E, Stokes JA, 3rd, et al. Resveratrol induces mitochondria-mediated, caspase-independent apoptosis in murine prostate cancer cells. Oncotarget 2017; 8(13): 2089520908.

34. Kim YA, Choi BT, Lee YT, et al. Resveratrol inhibits cell proliferation and induces apoptosis of human breast carcinoma MCF-7 cells. Oncol Rep 2004; 11(2): 441-446.

35. Luyten $\mathrm{T}$, Welkenhuyzen $\mathrm{K}$, Roest $\mathrm{G}$, et al. Resveratrol-induced autophagy is dependent on IP3Rs and on cytosolic Ca2+. BBAMol Cell Res 2017; 1864(6): 947-956.

36. Varoni EM, Lo Faro AF, Sharifi-Rad J, et al. Anticancer molecular mechanisms of resveratrol. Front Nutr 2016; 3: 8-8.

37. Feitelson MA, Arzumanyan A, Kulathinal RJ, et al. Sustained proliferation in cancer: Mechanisms and novel therapeutic targets. Semin Cancer Biol 2015; 35: S25-S54.

38. Eng S-K, Loh THT, Goh B-H, et al. KRAS as Potential Target in Colorectal Cancer Therapy, in Natural Bio-active Compounds. 2019, Springer: New York, USA. p. 389-424.

39. Yusof AM, Tieng FYF, Muhammad R, et al. In-depth characterization of miRNome in papillary thyroid cancer with BRAF V600E mutation. Prog Microbes Mol Biol 2020; 3(1)

40. Vergara D, Simeone P, Toraldo D, et al. Resveratrol downregulates Akt/GSK and ERK signalling pathways in OVCAR-3 ovarian cancer cells. Mol Biosyst 2012; 8(4): 1078 1087.

41. Lin H, Xiong W, Zhang X, et al. Notch-1 activation-dependent p53 restoration contributes to resveratrol-induced apoptosis in glioblastoma cells. Oncol Rep 2011; 26(4): 925-930.

42. Lin H-Y, Lansing L, Merillon J-M, et al. Integrin $\alpha \mathrm{V} \beta 3$ contains a receptor site for resveratrol. FASEB J 2006; 20(10): 1742 1744.

43. Zhong L-X, Li H, Wu M-L, et al. Inhibition of STAT3 signaling as critical molecular event in resveratrol-suppressed ovarian cancer cells. J Ovarian Res 2015; 8(1): 1-11.

44. Khanzadeh $\mathrm{T}$, Hagh MF, Talebi M, et al. Investigation of $\mathrm{BAX}$ and BCL2 expression and apoptosis in a resveratrol- and prednisolone-treated human T-ALL cell line, CCRF-CEM Blood Res 2018; 53(1): 53-60.

45. Mahyar-Roemer M, Köhler H and Roemer K. Role of Bax in resveratrol-induced apoptosis of colorectal carcinoma cells. BMC Cancer 2002; 2: 27 .

46. Gavrilas LI, Cruceriu D, Ionescu C, et al. Pro-apoptotic genes as new targets for single and combinatorial treatments with resveratrol and curcumin in colorectal cancer. Food Funct 2019 10(6): 3717-3726.

47. Park D, Jeong H, Lee MN, et al. Resveratrol induces autophagy by directly inhibiting mTOR through ATP competition. Sci Rep 2016; 6(1): 21772

48. Vidaček NŠ, Nanić L, Ravlić S, et al. Telomeres, Nutrition, and Longevity: Can We Really Navigate Our Aging? J Gerontol
2017: 73(1): 39-47.

49. Mirzazadeh A, Kheirollahi M, Farashahi E, et al. Assessment effects of resveratrol on human telomerase reverse transcriptase messenger Ribonucleic Acid transcript in human Glioblastoma. Adv Biomed Res 2017; 6: 73-73.

50. Wang XB, Zhu L, Huang J, et al. Resveratrol-induced augmentation of telomerase activity delays senescence of endothelial progenitor cells. Chin Med J (Engl) 2011; 124(24) $4310-4315$.

51. Weidner N, Semple JP, Welch WR, et al. Tumor angiogenesis and metastasis--correlation in invasive breast carcinoma. N Engl J Med 1991; 324(1): 1-8.

52. Trapp V, Parmakhtiar B, Papazian V, et al. Anti-angiogenic effects of resveratrol mediated by decreased VEGF and increased TSP1 expression in melanoma-endothelial cell co-culture. Angiogenesis 2010; 13(4): 305-315.

53. Mikuła-Pietrasik J, Kuczmarska A, Kucińska M, et al. Resveratrol and its synthetic derivatives exert opposite effects on mesothelia cell-dependent angiogenesis via modulating secretion of VEGF and IL-8/CXCL8. Angiogenesis 2012; 15(3): 361-376.

54. Lee SH, Koo BS, Park SY, et al. Anti-angiogenic effects of resveratrol in combination with 5-fluorouracil on B16 murine melanoma cells. Mol Med Report 2015(12): 2777-2783.

55. Wong JC and Fiscus RR. Resveratrol at Anti-angiogenesis/ Anticancer Concentrations Suppresses Protein Kinase G Signaling and Decreases IAPs Expression in HUVECs. Anticancer Res 2015; 35(1): 273-281.

56. Kalluri R and Weinberg RA. The basics of epithelial-mesenchymal transition. J Clin Invest 2009; 119(6): 1420-1428.

57. Kim C-W, Hwang K-A and Choi K-C. Anti-metastatic potentia of resveratrol and its metabolites by the inhibition of epithelialmesenchymal transition, migration, and invasion of malignant cancer cells. Phytomedicine 2016; 23(14): 1787-1796.

58. Yuan L, Zhou M, Huang D, et al. Resveratrol inhibits the invasion and metastasis of colon cancer through reversal of epithelialmesenchymal transition via the AKT/GSK-3 $\beta /$ Snail signaling pathway. Mol Med Report 2019; 20(3): 2783-2795.

59. Ji Q, Liu X, Fu X, et al. Resveratrol Inhibits Invasion and Metastasis of Colorectal Cancer Cells via MALAT1 Mediated Wnt/ $\beta$-Catenin Signal Pathway. PLoS One 2013; 8(11): e78700.

60. Li K, Dias SJ, Rimando AM, et al. Pterostilbene acts through metastasis-associated protein 1 to inhibit tumor growth, progression and metastasis in prostate cancer. PLoS One 2013; 8(3): e57542.

61. Lye K-L, Tan LT-H and Yap H-M. Insight of microRNA role in Colorectal Cancer. Prog Microbes Mol Biol 2020; 3(1).

62. Fernandes GFS, Silva GDB, Pavan AR, et al. Epigenetic Regulatory Mechanisms Induced by Resveratrol. Nutrients 2017; 9(11).

63. Mirza S, Sharma G, Parshad R, et al. Expression of DNA methyltransferases in breast cancer patients and to analyze the effect of natural compounds on DNA methyltransferases and associated proteins. J Breast Cancer 2013; 16(1): 23-31.

64. Kala R and Tollefsbol TO. A Novel Combinatorial Epigenetic Therapy Using Resveratrol and Pterostilbene for Restoring Estrogen Receptor- $\alpha(\mathrm{ER} \alpha)$ Expression in ER $\alpha$-Negative Breast Cancer Cells. PLoS One 2016; 11(5): e0155057.

65. Perwez Hussain S and Harris CC. Inflammation and cancer: An ancient link with novel potentials. Int J Cancer 2007; 121(11): 2373-2380.

66. Colotta F, Allavena P, Sica A, et al. Cancer-related inflammation, the seventh hallmark of cancer: Links to genetic instability. Carcinogenesis 2009; 30(7): 1073-1081.

67. Tili E and Michaille J-J. Resveratrol, MicroRNAs, inflammation and Cancer. J Nucleic Acids 2011; 2011: 102431.

68. Kim C, Baek SH, Um JY, et al. Resveratrol attenuates constitutive STAT3 and STAT5 activation through induction of PTPE and SHP-2 tyrosine phosphatases and potentiates sorafenib-induced apoptosis in renal cell carcinoma. BMC Nephrol 2016; 17: 19.

69. Wen $\mathrm{S}, \mathrm{Li} \mathrm{H}, \mathrm{Wu} \mathrm{ML}$, et al. Inhibition of NF-kB signaling commits resveratrol-treated medulloblastoma cells to apoptosis without neuronal differentiation. J Neurooncol 2011; 104(1) 169-177.

70. Saunier E, Antonio S, Regazzetti A, et al. Resveratrol reverses the Warburg effect by targeting the pyruvate dehydrogenase complex in colon cancer cells. Sci Rep 2017; 7(1): 6945.

71. Christofk HR, Vander Heiden MG, Harris MH, et al. The M2 splice isoform of pyruvate kinase is important for cance metabolism and tumour growth. Nature 2008; 452(7184): 230 233

72. McFate T, Mohyeldin A, Lu H, et al. Pyruvate dehydrogenase complex activity controls metabolic and malignant phenotype in cancer cells. J Biol Chem 2008; 283(33): 22700-22708.

73. Kayne FJ and Price NC. Amino acid effector binding to rabbit muscle pyruvate kinase. Arch Biochem Biophys 1973; 159(1): 292-296.

74. Iqbal MA and Bamezai RNK. Resveratrol inhibits cancer cell metabolism by down regulating pyruvate kinase M2 via inhibition of mammalian target of rapamycin. PLoS One 2012; 7(5): e36764-e36764.

75. S.M. Bauer-Wu and Post-White J. Immunology, in Cancer Nursing: Principles and Practice, C.H. Yarbro, M.H. Frogge, 
and M. Goodman, Editors. 2005, Jones \& Bartlett: Sudbury, MA. p. 27-39.

76. Hede K. Superhighway or blind alley? The cancer genome atlas releases first results. J Natl Cancer Inst 2008; 100(22): 1566-1569.

77. Malaguarnera L. Influence of Resveratrol on the Immune Response. Nutrients 2019; 11(5).

78. Lu CC and Chen JK. Resveratrol enhances perforin expression and NK cell cytotoxicity through NKG2D-dependent pathways. J Cell Physiol 2010; 223(2): 343-51.

79. Jhou JP, Chen SJ, Huang HY, et al. Upregulation of Fc $\gamma$ RIIB by resveratrol via NF- $\kappa B$ activation reduces B-cell numbers and ameliorates lupus. Exp Mol Med 2017; 49(9): e381.

80. Lee-Chang C, Bodogai M, Martin-Montalvo A, et al. Inhibition of breast cancer metastasis by resveratrol-mediated inactivation of tumor-evoked regulatory B cells. J Immunol 2013; 191(8): 41414151 .

81. Williams LD, Burdock GA, Edwards JA, et al. Safety studies conducted on high-purity trans-resveratrol in experimental animals. Food Chem Toxicol 2009; 47(9): 2170-2182.
82. Crowell JA, Korytko PJ, Morrissey RL et al Resveratrol-associated renal toxicity. Toxicol Sci 2004; 82(2): 614-619.

83. Howells LM, Berry DP, Elliott PJ, et al. Phase I randomized, doubleblind pilot study of micronized resveratrol (SRT501) in patients with hepatic metastases--safety, pharmacokinetics, and pharmacodynamics. Cancer Prev Res (Phila) 2011; 4(9): 1419-1425.

84. Popat R, Plesner T, Davies F, et al. A phase 2 study of SRT501 (resveratrol) with bortezomib for patients with relapsed and or refractory multiple myeloma. Br J Haematol 2013; 160(5): 714-717.

85. Nguyen AV, Martinez M, Stamos MJ, et al. Results of a phase I pilot clinical trial examining the effect of plant-derived resveratrol and grape powder on Wnt pathway target gene expression in colonic mucosa and colon cancer. Cancer Manag Res 2009; 1: 25-37.

86. Brown VA, Patel KR, Viskaduraki M, et al. Repeat dose study of the cancer chemopreventive agent resveratrol in healthy volunteers: Safety, pharmacokinetics, and effect on the insulin-like growth factor axis. Cancer Res 2010; 70(22): 9003-9011. 